\title{
Effects of Qing Hua Chang Yin on lipopolysaccharide-induced intestinal epithelial tight junction injury in Caco-2 cells
}

\author{
WENYI FANG $^{1 *}$, PEILIN ZHAO $^{1^{*}}$, ALING SHEN $^{2-4 *}$, LIYA LIU $^{2-4}$, HONGWEI CHEN $^{2-4}$, YOUQIN CHEN $^{2-4}$, \\ JUN PENG ${ }^{2,3}$, THOMAS J. SFERRA ${ }^{4}$, SENTHILKUMAR SANKARARAMAN ${ }^{4}$, YUNFENG LUO $^{1}$ and XIAO KE \\ ${ }^{1}$ Spleen and Stomach Research Room, Second People's Hospital Affiliated to Fujian University of \\ Traditional Chinese Medicine, Fuzhou, Fujian 350003; ${ }^{2}$ Academy of Integrative Medicine; \\ ${ }^{3}$ Fujian Key Laboratory of Integrative Medicine, Geriatric Fujian University of Traditional Chinese Medicine, \\ Fuzhou, Fujian 350122, P.R. China; ${ }^{4}$ Department of Pediatrics, Case Western Reserve University \\ School of Medicine, Rainbow Babies and Children's Hospital, Cleveland, OH 44106, USA
}

Received February 5, 2020; Accepted November 25, 2020

DOI: $10.3892 / \mathrm{mmr} .2021 .11844$

\begin{abstract}
Disruption of the intestinal mucosal barrier integrity is a pathogenic process in inflammatory bowel disease (IBD) development, and is therefore considered a drug discovery target for IBD. The well-known traditional Chinese formulation Qing Hua Chang Yin (QHCY) has been suggested as a potential therapeutic agent for the treatment of ulcerative colitis. However, the possible underlying molecular mechanisms regarding its therapeutic effect remain unclear. Consequently, the present study investigated the effects of QHCY on lipopolysaccharide (LPS)-induced loss of intestinal epithelial barrier integrity in vitro using the Caco-2 cell model of intestinal epithelium. QHCY reversed the LPS-induced decrease in transepithelial electrical resistance and significantly alleviated the increased fluorescently-labeled dextran 4 flux caused by LPS. Moreover, QHCY upregulated the mRNA and protein expression levels of occludin, zona occludens-1 and claudin-1 in LPS-exposed Caco-2 cells. In conclusion, QHCY was able to protect intestinal epithelial barrier integrity following an inflammatory insult; the protective effects of QHCY may be mediated by modulation of the expression of tight junction proteins.
\end{abstract}

Correspondence to: Dr Yunfeng Luo or Professor Xiao Ke, Spleen and Stomach Research Room, Second People's Hospital Affiliated to Fujian University of Traditional Chinese Medicine, 282 Wusi Road, Fuzhou, Fujian 350003, P.R. China

E-mail: renxiaoyao1949@163.com

E-mail:drkxkx@163.com

*Contributed equally

Abbreviations: IBD, inflammatory bowel disease; QHCY, Qing Hua Chang Yin; TJ, tight junction; UC, ulcerative colitis; TCM, Traditional Chinese Medicine

Key words: Qing Hua Chang Yin, Traditional Chinese Medicine, ulcerative colitis, tight junction

\section{Introduction}

Inflammatory bowel disease (IBD) most commonly refers to ulcerative colitis and Crohn's disease, which are conditions characterized by chronic gastrointestinal tract inflammation (1). IBD has a multifactorial etiology that involves the interplay of environmental, genetic and immunological factors (2). Its common pathogenic feature is disruption of the integrity of the intestinal epithelial barrier (3). Under normal conditions, several integral cellular proteins that maintain robust intercellular connections between epithelial cells support the intestinal mucosal barrier (4). The barrier is mainly composed of intercellular junctional complexes (5-7), which consist of tight junction (TJ) proteins (occludin and claudin-1) interacting with the central protein zona occludens (ZO)-1. TJ disruption leads to disturbances in the paracellular barrier and an increase in intestinal epithelial paracellular permeability. This alteration in permeability causes potential harmful antigens and luminal bacteria to penetrate the intestine, resulting in the initiation and acceleration of the mucosal inflammation in IBD (8-11). Thus, therapies that attenuate intestinal barrier dysfunction could effectively treat IBD (10-12).

Natural products commonly used in Traditional Chinese Medicine (TCM) have gained an increased medical interest worldwide, due to their potent anti-inflammatory role (13-15). One well-known traditional Chinese formula is Qing Hua Chang Yin (QHCY), which is composed of Coptis chinensis Franch, Herba et Gemma Agrimoniae, Radix Sanguisorbae, Magnolia officinalis, Radix Paeoniae Rubra, Elettaria cardamomum, Semen Coicis, Artemisia capillaris Thunb, Semen Dolichoris Album, Herba Eupatorii Fortunei and Poria cocos. In TCM, QHCY is considered beneficial in the treatment of $\mathrm{UC}$; therefore, QHCY has been used in the management of UC for several years in China (16-21).

In mice, QHCY has been reported to alleviate the clinical and histological manifestations of dextran sulfate sodium-induced colitis (22-24); this effect was revealed to be partly mediated by a reduction in inflammatory cytokine release via the TLR4/NF- $\kappa$ B and IL-6/STAT3 signaling pathways. However, to the best of our knowledge, the effect 
of QHCY on intestinal epithelial barrier function is unknown. To elucidate the therapeutic mechanism underlying the effects of QHCY, the present study investigated the in vitro effects of $\mathrm{QHCY}$ on the intestinal epithelial barrier.

\section{Materials and methods}

Materials and reagents. Dulbecco's modified Eagle's medium (DMEM; cat. no. C11995500BT), fetal bovine serum (FBS; cat. no. 10091148), penicillin-streptomycin (cat. no. 15070063) and trypsin-ethylenediaminetetraacetic acid (cat. no. 25200072) were purchased from Gibco; Thermo Fisher Scientific, Inc. Lipopolysaccharide (LPS; Escherichia coli serotype 055:B5; cat. no. L6529) and fluorescein isothiocyanate-dextran (FITC-dextran 4: FD4; cat. no. FD4) were acquired from Sigma-Aldrich; Merck KGaA. The M-PER Mammalian Protein Extraction Reagent (cat. no. 78501) and BCA assay kit (cat. no. 23227) were purchased from Thermo Fisher Scientific, Inc. Anti-ZO-1 (cat. no. GTX108592) was obtained from GeneTex, Inc., and anti-occludin (cat. no. 13409-1-AP) and anti-claudin-1 (cat. no. 13050-1-AP) antibodies were obtained from Proteintech Group, Inc. Moreover, anti- $\beta$-actin antibody (cat. no. 4970) and horseradish peroxidase (HRP)-conjugated secondary antibody (cat. no. 7074) were acquired from Cell Signaling Technology, Inc. The human TNF- $\alpha$ ELISA kit (cat. no. 430204) was obtained from BioLegend, Inc. RNAiso plus reagent and the PrimeScriptRT reagent kit were obtained from Takara Biotechnology Co., Ltd. Unless otherwise noted, all other reagents were obtained from Sigma-Aldrich; Merck KGaA.

QHCY preparation. QHCY was prepared as previously described (23). Briefly, the following dehydrated amounts of each component were used in the preparation: $33 \mathrm{~g}$ Coptis chinensis Franch, $220 \mathrm{~g}$ Herba et Gemma Agrimoniae, 110 g Radix Paeoniae Rubra, $100 \mathrm{~g}$ Radix Sanguisorbae, $110 \mathrm{~g}$ Magnolia officinalis, 56 g Elettaria cardamomum, $110 \mathrm{~g}$ Herba Eupatorii Fortunei, $110 \mathrm{~g}$ Artemisia capillaris Thunb., $110 \mathrm{~g}$ Semen Dolichoris Album, $220 \mathrm{~g}$ Semen Coicis and $220 \mathrm{~g}$ Poria cocos (obtained from the Department of Pharmacy, Second People's Hospital Affiliated to Fujian University of Traditional Chinese Medicine, Fuzhou, Fujian, China). The mixture was extracted by boiling three times in 21 distilled water. The extracts were filtered and concentrated by boiling to a final volume of 11 . The stock concentration of QHCY was $1.4 \mathrm{~g} / \mathrm{ml}$.

Cell culture. Cells were cultured as previously described (23). Human colon cancer Caco-2 cells (cat. no. HTB37) were purchased from the American Type Culture Collection. The cells were cultured in DMEM supplemented with $10 \%(\mathrm{v} / \mathrm{v})$ FBS, glucose $(1 \mathrm{~g} / \mathrm{l})$, penicillin $(50 \mathrm{U} / \mathrm{ml})$ and streptomycin $(50 \mu \mathrm{g} / \mathrm{ml})$ in a humidified incubator containing $5 \% \mathrm{CO}_{2}$ at $37^{\circ} \mathrm{C}$. Subsequently, cells were subcultured at $85-90 \%$ confluence and differentiated into enterocyte-like cells 18-20 days later, as described previously $(22,23)$. Fully differentiated cells were used for further experiments.

Cell Counting Kit-8 (CCK-8) assay. Cell viability was assessed using CCK-8 (Dojindo Technologies, Inc.). Differentiated Caco-2 cells in 96-well plates were treated with the indicated concentrations of LPS $(0-80 \mu \mathrm{g} / \mathrm{ml})$ for $24 \mathrm{~h}$ at $37^{\circ} \mathrm{C}$. Subsequently, $10 \mu \mathrm{l} \mathrm{CCK}-8$ was added to each well and incubated for $2 \mathrm{~h}$ at $37^{\circ} \mathrm{C}$. Absorbance was measured at $405 \mathrm{~nm}$ using a fluorescence plate reader (Model ELx80; BioTek Corporation).

TNF- $\alpha$ ELISA assay. As described previously (23), differentiated Caco-2 cells in 24-well plates were incubated with QHCY (10 and $50 \mu \mathrm{g} / \mathrm{ml})$ for $1 \mathrm{~h}$ before stimulation with LPS $(1 \mu \mathrm{g} / \mathrm{ml})$ for $24 \mathrm{~h}$ at $37^{\circ} \mathrm{C}$. Subsequently, the supernatants were collected by centrifuging the cell culture medium at $3,000 \mathrm{xg}$ for $10 \mathrm{~min}$ at room temperature. Using a human TNF- $\alpha$ ELISA kit, the production of TNF- $\alpha$ from Caco- 2 cells was measured, according to the manufacturer's instructions. Absorbance was read at $450 \mathrm{~nm}$ using a fluorescence plate reader. All samples were assessed in triplicate.

Transepithelial electrical resistance (TEER) measurement. Caco- 2 cells $\left(5 \times 10^{4}\right.$ cells/well) were seeded in the upper chamber of 24-well plates containing Transwell inserts and cultured for 18-20 days before experimentation; the culture medium was changed every other day. To determine TJ formation, the TEER of the Caco-2 cell monolayer was measured using a Millicell ERS (EMD Millipore). For the subsequent experiments, monolayers with TEER between 400 and $500 \Omega \mathrm{cm}^{2}$ were used, and were treated with QHCY (10 and $50 \mu \mathrm{g} / \mathrm{ml})$ for $1 \mathrm{~h}$ before LPS $(1 \mu \mathrm{g} / \mathrm{ml})$ stimulation for $24 \mathrm{~h}$ at $37^{\circ} \mathrm{C}$. TEER was measured before and after treatment. Moreover, triplet cell monolayers were assessed for each experimental group. TEER changes during experimental conditions were calculated as the percentage of baseline levels.

Measurement of permeability. To evaluate paracellular permeability, the fluorescently-labeled dextran 4 (FD4: cat. no. FD4; Sigma-Aldrich; Merck KGaA ) flux from apical to basolateral was measured as previously described, with minor modifications (25). Briefly, Caco- 2 cells $\left(5 \times 10^{4}\right.$ cells/well) were seeded in the upper chamber of 24-well plates containing Transwell inserts and were cultured for 18-20 days before experimentation; the culture medium in the lower chamber was changed every other day. The TEER of the Caco-2 cell monolayer was measured using a Millicell ERS (EMD Millipore). For the subsequent experiments, the cell monolayers with TEER between 400 and $500 \Omega \mathrm{cm}^{2}$ were used, and treated with QHCY and LPS as aforementioned. The medium was then removed, and $200 \mu 1 \mathrm{FD} 4(5 \mathrm{mg} / \mathrm{ml})$ and $500 \mu 1$ PBS was added to the apical and basolateral compartments of each Transwell insert, respectively. After $2 \mathrm{~h}$ of incubation at $37^{\circ} \mathrm{C}$, $100 \mu \mathrm{l}$ was removed from the basolateral compartment and transferred to 96-well plates. Subsequently, FD4 concentration was determined using a fluorescence plate reader at an excitation wavelength of $480 / 492 \mathrm{~nm}$ and an emission wavelength of $520 / 525 \mathrm{~nm}$. All samples were assessed three times.

Reverse transcription-quantitative PCR (RT-qPCR) assay. Differentiated Caco-2 cells in 6-well plates were incubated with QHCY and LPS as aforementioned. According to the manufacturer's instructions, total cellular RNA was extracted using RNAiso plus reagent (Takara Biotechnology Co., Ltd.) and RT was conducted using the PrimeScript RT reagent kit (Takara Biotechnology Co., Ltd.). The mRNA expression levels of ZO-1, 
Table I.Primer sequences for reverse transcription-quantitative PCR.

\begin{tabular}{ll}
\hline Gene name & \multicolumn{1}{c}{ Sequences (5'-3') } \\
\hline ZO-1 & $\begin{array}{l}\text { Forward: AGCCTGCAAAGCCAGCTCA } \\
\text { Reverse: AGTGGCCTGGATGGGTTCATAG }\end{array}$ \\
Claudin-1 & Forward: GCATGAAGTGTATGAAGTGCTTGGA \\
& Reverse: CGATTCTATTGCCATACCATGCTG \\
Occludin & Forward: CTTTGGCTACGGAGGTGGCTAT \\
& Reverse: CTTTGGCTGCTCTTGGGTCTG \\
GAPDH & Forward: GCACCGTCAAGGCTGAGAAC \\
& Reverse: ATGGTGGTGAAGACGCCAGT
\end{tabular}

ZO-1, zona occludens-1.

occludin and claudin-1 were determined by qPCR using SYBR green dye (Thermo Fisher Scientific, Inc.) and the ABI 7500 fast sequence detection system (Applied Biosystems; Thermo Fisher Scientific, Inc.). An initial denaturation step was performed at $95^{\circ} \mathrm{C}$ for $30 \mathrm{sec}$, followed by 40 cycles at $95^{\circ} \mathrm{C}$ for $3 \mathrm{sec}$ and annealing at $60^{\circ} \mathrm{C}$ for $30 \mathrm{sec}$. GAPDH served as an internal control. The sequences of primers used for QPCR are provided in Table I. The mRNA expression levels of genes of interest were quantified using $2^{-\Delta \Delta C q}$ analysis (26). mRNA expression levels are expressed as fold change relative to the control group.

Western blot analysis. Differentiated Caco-2 cells in 6-well plates were incubated with QHCY (10 and $50 \mu \mathrm{g} / \mathrm{ml})$ for $1 \mathrm{~h}$ before stimulation with LPS $(1 \mu \mathrm{g} / \mathrm{ml})$ for $24 \mathrm{~h}$ at $37^{\circ} \mathrm{C}$. A mammalian cell lysis buffer containing a phosphatase inhibitor and a protease inhibitor cocktail (EMD Millipore) (23) was used to lyse the differentiated Caco-2 cells incubated with QHCY and LPS for $24 \mathrm{~h}$ at $37^{\circ} \mathrm{C}$. Lysed cells were then centrifuged at $12,000 \mathrm{xg}$ for $15 \mathrm{~min}$ at $4^{\circ} \mathrm{C}$ and the supernatants were collected. Protein concentrations were measured using the BCA protein assay kit. Equal amounts of protein $(50 \mu \mathrm{g})$ from each sample were resolved on $12 \%$ Tris-glycine gels and transferred onto nitrocellulose membranes. The membranes were blocked for $1 \mathrm{~h}$ at room temperature with SuperBlock buffer (Thermo Fisher Scientific, Inc.) and were then incubated with primary antibodies against ZO-1 (rabbit, polyclonal; 1:1,000), occludin (rabbit, polyclonal; 1:1,000), claudin-1 (rabbit, polyclonal; 1:1,000) and $\beta$-actin (rabbit, polyclonal; $1: 2,000$ ) at $4^{\circ} \mathrm{C}$ overnight. Subsequently, membranes were incubated with the appropriate anti-rabbit IgG, HRP-linked secondary antibody $(1: 5,000)$ for $1 \mathrm{~h}$ at room temperature. Thereafter, the membranes were visualized using enhanced chemiluminescence using SuperSignal ${ }^{\mathrm{TM}}$ West Dura Extended Duration Substrate (cat. no. 34076; Thermo Fisher Scientific, Inc.). Images were captured using an imaging system (Bio-Rad Laboratories, Inc.). The protein levels were analyzed with ImageJ Software (National Institutes of Health). $\beta$-actin protein expression was used as an internal control.

Statistical analysis. All data were analyzed using SPSS software (22.0) for Windows (IBM Corp.). Data are presented as

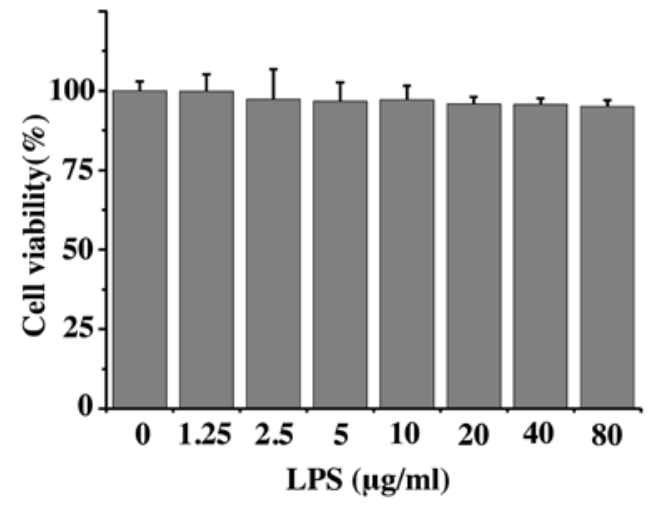

Figure 1. Effects of LPS on cell viability. Cells were treated with various LPS concentrations for $24 \mathrm{~h}$ and cytotoxicity was measured by Cell Counting Kit- 8 assay. Data were normalized to the control group and are presented as the mean \pm SD from at least three independent experiments. LPS, lipopolysaccharide.

the mean $\pm \mathrm{SD}$ of at least three independent experiments. The significance of differences among groups that conformed to a normal distribution was determined by one-way ANOVA followed by Tukey's post hoc test. Two-tailed $\mathrm{P}<0.05$ was considered to indicate a statistically significant difference.

\section{Results}

LPS does not affect Caco- 2 cell viability. Caco-2 cell viability was assessed following exposure to LPS (Fig. 1); cell viability was not affected by even the highest concentration of LPS tested $(80 \mu \mathrm{g} / \mathrm{ml})$. These findings indicated that the observations made in subsequent experiments were not caused by LPS-induced cell death. A concentration of $10 \mu \mathrm{g} / \mathrm{ml}$ LPS was used for all further experiments.

QHCY inhibits the LPS-induced production of the proinflammatory cytokine TNF- $\alpha$. TNF- $\alpha$ has been reported to participate in the pathogenesis of various inflammatory disorders, including IBD (26). When exposed to LPS, Caco-2 cells produced increased levels of TNF- $\alpha$ compared with in the control group. To demonstrate the biological activity of the QHCY preparation, the effects of QHCY on TNF- $\alpha$ production by LPS-exposed Caco-2 cells were assessed (Fig. 2). As anticipated, LPS induced TNF- $\alpha$ secretion from the Caco-2 cells; however, QHCY significantly suppressed LPS-induced TNF- $\alpha$ secretion, which is consistent with our previous observation (24).

QHCY inhibits inflammation-induced paracellular permeability in Caco-2 cell monolayers. To investigate whether $\mathrm{QHCY}$ can preserve the intestinal epithelial barrier during inflammation, Caco-2 cell monolayers were pretreated with QHCY before LPS exposure (Fig. 3). LPS significantly decreased the TEER of the Caco- 2 cell monolayers compared with that in the control group (control, $100 \pm 2.3 \%$; LPS, $39.8 \pm 7.5 \%$ ), indicating an increase in permeability. However, pretreatment with QHCY ameliorated the LPS-induced decrease in TEER, demonstrating that the normal barrier function was protected by QHCY treatment $(10 \mu \mathrm{g} / \mathrm{ml}$ QHCY, 78.0 $\pm 6.0 \% ; 50 \mu \mathrm{g} / \mathrm{ml}$ QHCY, 96.4 $\pm 7.6 \%$ ). Moreover, as another measure of Caco-2 


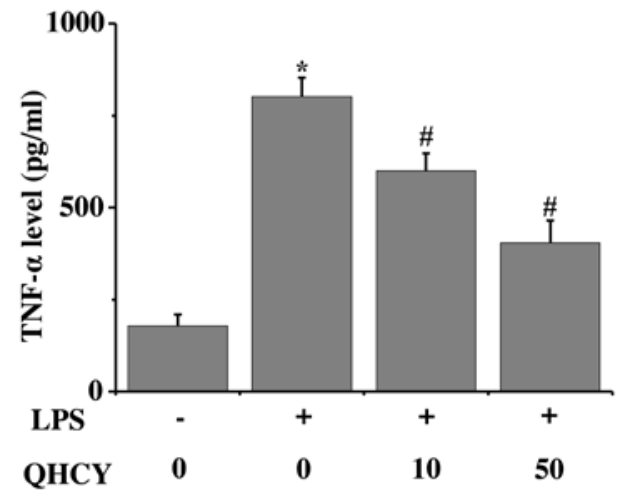

Figure 2. Effects of QHCY on TNF- $\alpha$ secretion from LPS-stimulated Caco-2 cells. TNF- $\alpha$ levels within the culture medium were determined by ELISA. Data are presented as the mean $\pm \mathrm{SD}$. ${ }^{*} \mathrm{P}<0.05$ vs. control group; ${ }^{*} \mathrm{P}<0.05$ vs. LPS group. LPS, lipopolysaccharide; QHCY, Qing Hua Chang Yin.

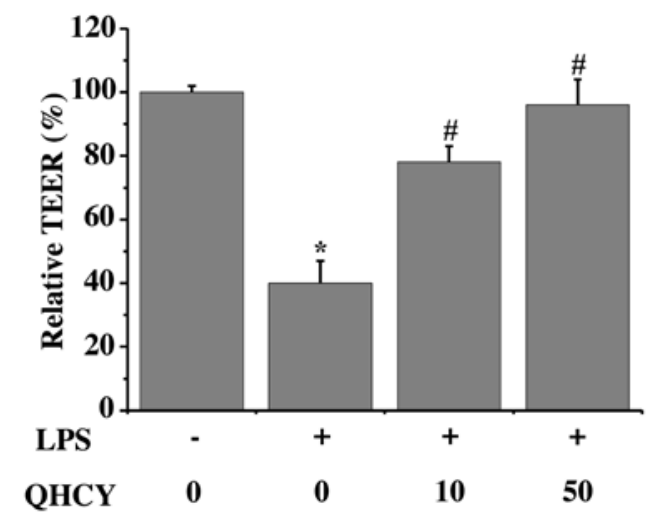

Figure 3. Effects of QHCY on relative TEER of Caco-2 monolayers following LPS exposure. Caco- 2 monolayers were treated with the indicated concentrations $(\mu \mathrm{g} / \mathrm{ml})$ of QHCY. Relative TEER was determined by comparing the TEER before LPS addition to that at the end of the experimental period. Data are presented as the mean $\pm \mathrm{SD}$ of three replicates in three independent experiments. ${ }^{*} \mathrm{P}<0.05$ vs. control group; ${ }^{\# P}<0.05$ vs. LPS group. LPS, lipopolysaccharide; QHCY, Qing Hua Chang Yin; TEER, transepithelial electrical resistance.

monolayer permeability, FD4 flux was measured (Fig. 4). Consistent with the TEER results, LPS significantly increased FD4 flux compared with that in the control group (control, $1.04 \pm 0.11 \mu \mathrm{g} / \mathrm{ml}$; LPS, $12.52 \pm 0.80 \mu \mathrm{g} / \mathrm{ml}$ ). Pretreatment with QHCY provided protection against the LPS-induced hyperpermeability of Caco-2 cell monolayers $(10 \mu \mathrm{g} / \mathrm{ml}$ QHCY, $8.40 \pm 0.97 \mu \mathrm{g} / \mathrm{ml} ; 50 \mu \mathrm{g} / \mathrm{ml}$ QHCY, $2.57 \pm 0.64 \mu \mathrm{g} / \mathrm{ml})$. Taken together, these findings suggested that QHCY could contribute to the maintenance of mucosal barrier integrity against inflammation-induced permeability.

QHCY prevents LPS-induced disruption of TJs in Caco-2 cell monolayers. The present study investigated the expression levels of TJ-associated factors by RT-qPCR and western blot analyses, in order to determine the mechanisms underlying the protective effect of QHCY on epithelial cell monolayer permeability. The effects of QHCY on the mRNA expression levels of ZO-1, occludin and claudin-1 in epithelial cells were determined by RT-qPCR. As shown in Fig. 5, the mRNA expression levels of occludin (Fig. 5A), ZO-1 (Fig. 5B) and

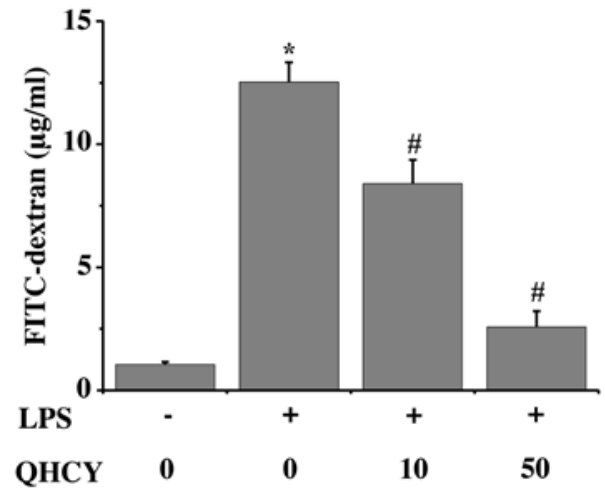

Figure 4. Effects of QHCY on FD4 flux in Caco-2 monolayers after LPS exposure. Caco-2 monolayers were treated with the indicated concentrations $(\mu \mathrm{g} / \mathrm{ml})$ of QHCY. Data are presented as the mean $\pm \mathrm{SD} .{ }^{*} \mathrm{P}<0.05$ vs. control group; ${ }^{\text {P }}<0.05$ vs. LPS group. LPS, lipopolysaccharide; QHCY, Qing Hua Chang Yin; FD4, fluorescently-labeled dextran 4.

claudin-1 (Fig. 5C) were significantly decreased after LPS treatment compared with those in the control group, whereas treatment with QHCY significantly reversed the effect of LPS on the expression levels of ZO-1, occludin and claudin-1. Similarly, the effects of QHCY on the protein expression levels of ZO-1, occludin and claudin-1 in epithelial cells were determined using western blot-ting. As shown in Fig. 6A and B, compared with in the control group, treatment with LPS induced a significant reduction in the protein expression levels of TJ-associated factors, ZO-1, occludin and claudin-1, which was reversed by the administration of QHCY. These findings suggested that preventing the reduction in the expression levels of TJ proteins may be the mechanism underlying the effects of QHCY on the LPS-induced increase in epithelial cell monolayer permeability.

\section{Discussion}

Despite recent advances in therapy, patients with IBD still suffer from disease manifestations stemming from unremitting active inflammation. Moreover, current therapies are related to significant potential adverse reactions, such as systemic immunosuppression, headache, nausea and fatigue $(27,28)$; therefore, alternative effective therapies for IBD are required. The anti-inflammatory effects of numerous natural products have gained considerable attention due to their relatively low toxicity (24). QHCY, which is a well-recognized traditional Chinese formula, has been used in clinical settings for treating several inflammatory disorders, including arthritis, hepatitis, cholecystitis and IBD (29). However, the mechanisms underlying the biological activity of QHCY remain to be elucidated. The barrier function of colonic mucosa is maintained by TJs and their molecular components, including ZO-1, occludin and claudin-1, and an increase in intestinal permeability is often documented in intestinal barrier dysfunction (30-32). Thus, the present study examined the effects of QHCY on cell permeability and TJ protein expression using an in vitro model of intestinal epithelium that has been used in similar studies (8,33-41).

Intestinal permeability serves a critical role in host defense (34). Patients with IBD exhibit increased intestinal 
A

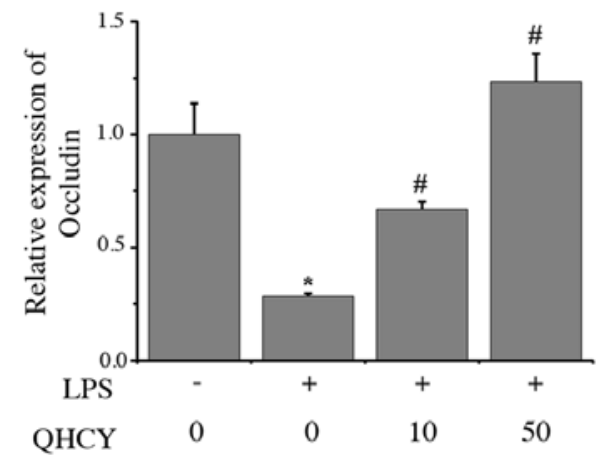

B

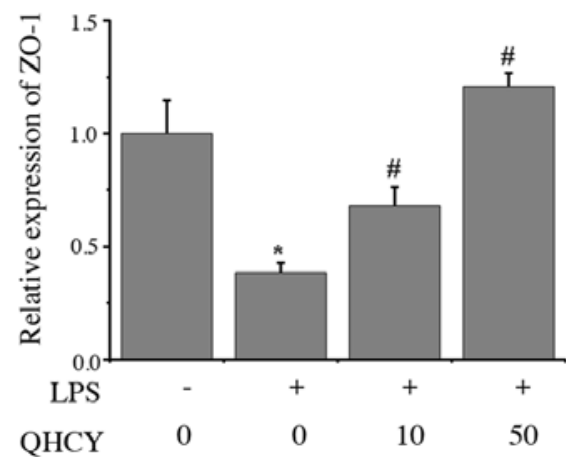

C

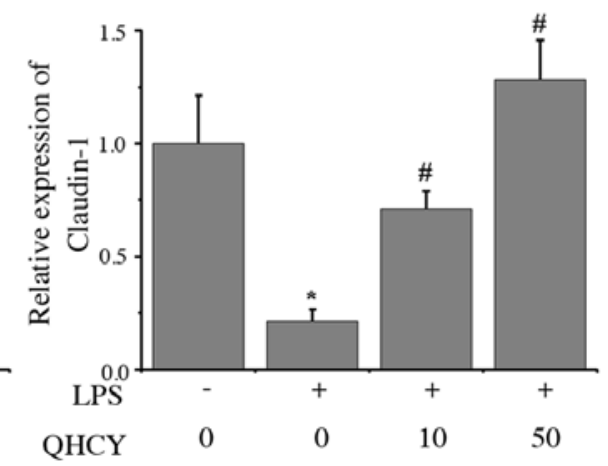

Figure 5. Effects of QHCY on the mRNA expression levels of occludin, ZO-1 and claudin-1 in LPS-exposed, differentiated Caco-2 cells treated with or without QHCY. (A) Occludin, (B) ZO-1 and (C) claudin-1 expression levels were identified by reverse transcription-quantitative PCR. GAPDH served as the internal control. Data are presented as the mean \pm SD. ${ }^{*} \mathrm{P}<0.05$ vs. control group; ${ }^{*} \mathrm{P}<0.05$ vs. LPS group. LPS, lipopolysaccharide; QHCY, Qing Hua Chang Yin; ZO-1, zona occludens-1.

A LPS QHCY

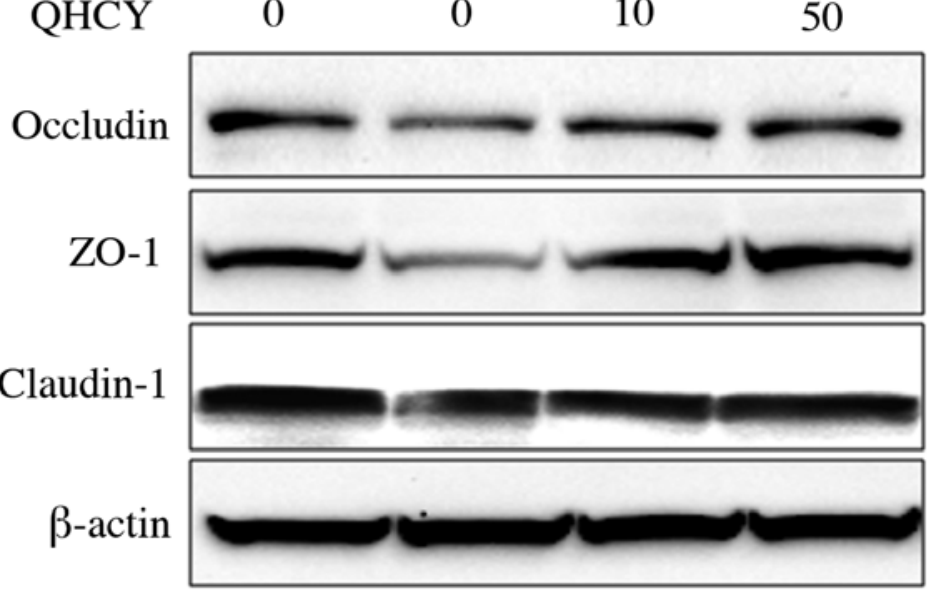

B

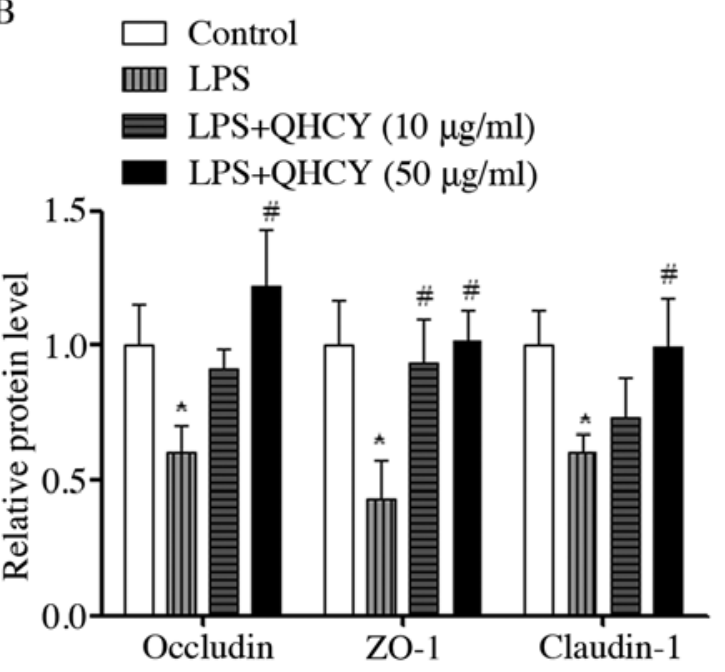

Figure 6. Effects of QHCY on the protein expression levels of occludin, ZO-1 and claudin-1 in LPS-exposed, differentiated Caco-2 cells treated with or without QHCY. (A) Occludin, ZO-1 and claudin-1 were detected by western blot analysis. $\beta$-actin served as the internal control. (B) Densitometric analysis. ${ }^{*} \mathrm{P}<0.05$ vs. control group; ${ }^{\#} \mathrm{P}<0.05$ vs. LPS group. LPS, lipopolysaccharide; QHCY, Qing Hua Chang Yin; ZO-1, zona occludens-1.

mucosal permeability, which is correlated with disease severity (8,35-37). In the present study, QHCY significantly alleviated LPS-induced increases in the permeability of epithelial cell monolayers. This effect was observed by both TEER and FD4 flux assays. Thus, QHCY may contribute to maintaining the integrity of the mucosal barrier during inflammatory insults.

The intestinal epithelial barrier consists of epithelial cells joined together by intercellular junctional complexes, which include the TJ proteins ZO-1, occludin and claudin-1 (5). These proteins are crucial for barrier function maintenance, and their expression has been shown to be reduced in response to inflammatory states, including in IBD (36-39). In IBD, claudin-1 expression was significantly decreased (42). As previously demonstrated that QHCY significantly reversed the DSS-induced downregulation of ZO-1, occludin, and claudin-1 in mRNA and protein levels in the mice (30). The present study revealed that LPS markedly suppressed the expression of ZO-1, occludin and claudin-1 at both the mRNA and protein expression levels in IEC, whereas QHCY significantly reversed this effect. Therefore, QHCY may regulate TJ expression to maintain mucosal barrier integrity. Possibly, the effects of QHCY observed on the expression levels of TJ proteins were indirect and caused by TNF- $\alpha$ activity suppression, since QHCY could inhibit the LPS-induced production of the proinflammatory cytokine TNF- $\alpha$. Notably, QHCY may exert potential anti-inflammatory effects and could be considered a useful therapy for the treatment of IBD.

In conclusion, QHCY reduced the LPS-induced secretion of TNF- $\alpha$ and reversed the increase in permeability of Caco-2 cell monolayers, thereby preserving the expression levels of ZO-1, occludin and claudin-1. Therefore, QHCY may be considered a potential therapeutic agent for the treatment of IBD, due to its direct suppressive effect on the secretion of proinflammatory cytokines and the maintenance of epithelial barrier function. However, further investigations should be 
conducted to determine the underlying potential mechanism of QHCY treatment for IBD.

\section{Acknowledgements}

Not applicable.

\section{Funding}

This study was supported by the National Natural Science Foundation of China (grant no. 81673731) and the Natural Science Foundation of Fujian Province (grant no. 2017J01302).

\section{Availability of data and materials}

The datasets used and/or analyzed during the current study are available from the corresponding author on reasonable request.

\section{Authors' contributions}

XK, TJS and JP acquired funding for the research. WF, PZ, AS, YL, SS and XK conceived and designed the experiments. WF, PZ, AS, LL, HC, SS and YC performed the experiments. WF, PZ, TS and AS analyzed the data. YC, TJS and JP acquired, interpreted the data and confirmed the authenticity of the raw data associated with the preparation of the manuscript. JP, TJS and SS wrote the manuscript. JP, YL, TJS and XK checked the manuscript. All authors read and approved the final manuscript.

\section{Ethics approval and consent to participate}

Not applicable.

\section{Patient consent for publication}

Not applicable.

\section{Competing interests}

The authors declare that they have no competing interests.

\section{References}

1. Strober W, Fuss I and Mannon P: The fundamental basis of inflammatory bowel disease. J Clin Invest 117: 514-521, 2007.

2. Talley NJ, Abreu MT, Achkar JP, Bernstein CN, Dubinsky MC, Hanauer SB, Kane SV, Sandborn WJ, Ullman TA and Moayyedi P; American College of Gastroenterology IBD Task Force: An evidence-based systematic review on medical therapies for inflammatory bowel disease. Am J Gastroenterol 106 (Suppl 1): S2-S25, quiz S26, 2011.

3. Lee JY, Wasinger VC, Yau YY, Chuang E, Yajnik V and Leong RW: Molecular pathophysiology of epithelial barrier dysfunction in inflammatory bowel diseases. Proteomes 6: E17, 2018.

4. Camilleri M, Madsen K, Spiller R, Greenwood-Van Meerveld B and Verne GN: Intestinal barrier function in health and gastrointestinal disease. Neurogastroenterol Motil 24: 503-512, 2012.

5. Ma TY, Iwamoto GK, Hoa NT, Akotia V, Pedram A, Boivin MA and Said HM: TNF-alpha-induced increase in intestinal epithelial tight junction permeability requires NF-kappa B activation. Am J Physiol Gastrointest Liver Physiol 286: G367-G376, 2004.

6. Ivanov AI, Nusrat A and Parkos CA: The epithelium in inflammatory bowel disease: Potential role of endocytosis of junctional proteins in barrier disruption. Novartis Found Symp 263: 115-124, discussion 124-132, 211-218, 2004.
7. Niessen CM: Tight junctions/adherens junctions: Basic structure and function. J Invest Dermatol 127: 2525-2532, 2007.

8. Turner JR: Intestinal mucosal barrier function in health and disease. Nat Rev Immunol 9: 799-809, 2009.

9. Laukoetter MG, Nava P, Lee WY, Severson EA, Capaldo CT, Babbin BA, Williams IR, Koval M, Peatman E, Campbell JA, et al: JAM-A regulates permeability and inflammation in the intestine in vivo. J Exp Med 204: 3067-3076, 2007.

10. Arrieta MC, Madsen K, Doyle J and Meddings J: Reducing small intestinal permeability attenuates colitis in the IL10 gene-deficient mouse. Gut 58: 41-48, 2009.

11. Edelblum KL and Turner JR: The tight junction in inflammatory disease: Communication breakdown. Curr Opin Pharmacol 9: 715-720, 2009.

12. Arnott ID, Kingstone $\mathrm{K}$ and Ghosh S: Abnormal intestinal permeability predicts relapse in inactive Crohn disease. Scand J Gastroenterol 35: 1163-1169, 2000.

13. Ahmad TB, Liu L, Kotiw M and Benkendorff K: Review of anti-inflammatory, immune-modulatory and wound healing properties of molluscs. J Ethnopharmacol 210: 156-178, 2018.

14. Gao L, Jia C, Zhang $\mathrm{H}$ and Ma C: Wenjing decoction (herbal medicine) for the treatment of primary dysmenorrhea: A systematic review and meta-analysis. Arch Gynecol Obstet 296: 679-689, 2017.

15. Zhang LJ,Zhu JY, Sun MY, Song YN, Rahman K, Peng C,Zhang M, Ye YM and Zhang H: Anti-inflammatory effect of Man-Pen-Fang, a Chinese herbal compound, on chronic pelvic inflammation in rats. J Ethnopharmacol 208: 57-65, 2017.

16. Wang XY and Tian DL: Etiological and pathological characteristics of ulcerative colitis and TCM differentiation and treatment. Beijing Zhong Yi Yao Da Xue Xue Bao 30: 554-559, 2007 (In Chinese).

17. Gong YP, Liu W, Ma GT, Hu HY, Xie JQ, Tang ZP, Hao WW, Bian H, Zhu LY, et al: Randomized control study of 'Qingchang Suppository' on ulcerative colitis. Shanghai Zhong Yi Yao Da Xue Xue Bao 21: 33-36, 2007 (In Chinese).

18. Fu NL and Huang JY: Progress of clinical research of traditional Chinese medicine for the treatment of ulcerative colitis. J Tradit Chin Med 40: 501-503, 1999 (In Chinese).

19. Li QG: An idea about treatment of ulcerative colitis by TCM methods. Beijing Zhong Yi 23: 149-150, 2004 (In Chinese).

20. Wang CH, Gao WY, Li YF, Chen SQ, Yang Z, Lu YP, Gong Y and Liu Y: Study of Fufangkushen colon-release capsule on ulcerative colitis of endo-retention of damp heat type. Xian Dai Zhong Xi Yi Jie He Za Zh 18: 13-15, 2009 (In Chinese).

21. Chen JT, Ke X, Fu XY, Wang WR, Hu GH and Yang CB: The clinical study of heat-clearing and damp-drying on the treatment of damp-heat ulcerative colitis. Zhongguo Zhong Xi Yi Jie He Xiao Hua Za Zh 17: 256-258, 2009 (In Chinese).

22. Ke X, Hu G, Fang W, Chen J, Zhang X, Yang C, Peng J, Chen Y and Sferra TJ: Qing Hua Chang Yin inhibits the LPS-induced activation of the IL-6/STAT3 signaling pathway in human intestinal Caco-2 cells. Int J Mol Med 35: 1133-1137, 2015.

23. Ke X, Chen J, Zhang X, Fang W, Yang C, Peng J, Chen Y and Sferra TJ: Qing Hua Chang Yin attenuates lipopolysaccharide-induced inflammatory response in human intestinal cells by inhibiting NF- $\kappa B$ activation. Exp Ther Med 6: 189-193, 2013.

24. Ke X, Zhou F, Gao Y, Xie B, Hu G, Fang W, Peng J, Chen Y and Sferra TJ: Qing Hua Chang Yin exerts therapeutic effects against ulcerative colitis through the inhibition of the TLR4/NF- $\kappa \mathrm{B}$ pathway. Int J Mol Med 32: 926-930, 2013.

25. Amasheh M, Grotjohann I, Amasheh S, Fromm A, Söderholm JD, Zeitz M, Fromm M and Schulzke JD: Regulation of mucosal structure and barrier function in rat colon exposed to tumor necrosis factor alpha and interferon gamma in vitro: A novel model for studying the pathomechanisms of inflammatory bowel disease cytokines. Scand J Gastroenterol 44: 1226-1235, 2009.

26. Livak KJ and Schmittgen TD: Analysis of relative gene expression data using real-time quantitative PCR and the $2(-\Delta \Delta \mathrm{C}(\mathrm{T}))$ Method. Methods 25: 402-408, 2001.

27. Berends SE, Strik AS, Löwenberg M, D'Haens GR and Mathôt RAA: Clinical Pharmacokinetic and Pharmacodynamic Considerations in the Treatment of Ulcerative Colitis. Clin Pharmacokinet 58: 15-37, 2019.

28. Kondamudi PK, Malayandi R, Eaga C and Aggarwal D: Drugs as causative agents and therapeutic agents in inflammatory bowel disease. Acta Pharm Sin B 3: 289-296, 2013.

29. Suzuki T: Regulation of intestinal epithelial permeability by tight junctions. Cell Mol Life Sci 70: 631-659, 2013.

30. Ke X, Liu L, Zhao P, Chen Y, Peng J, Fang W, Chen J, Hu G, Gao Y, Shen A, et al: The effects of Qing Hua Chang Yin on the epithelial tight junctions of mice with inflammatory bowel disease. Int J Clin Exp Med 12: 6864-6873, 2019. 
31. Liu J, Lu XJ, Tian XM, Shen XP and Bao XP: Antipyretic effects of Xinhuang Tablets on various animal fever models. Drugs Clin 4: 375-379, 2015 (In Chinese).

32. Chen C, Bao XP, Qiu CX, Wang CF, Nan SH, Huang WQ and Wang RG: Effects of Xinhuang tablets and its chinese medicine components on high uric acid mice caused by hypoxanthine. Strait Pharm J 1: 21-23, 2015 (In Chinese).

33. Putt KK, Pei R, White HM and Bolling BW: Yogurt inhibits intestinal barrier dysfunction in Caco-2 cells by increasing tight junctions. Food Funct 8: 406-414, 2017.

34. Gasparetto $M$ and Guariso G: Highlights in IBD epidemiology and its natural history in the paediatric age. Gastroenterol Res Pract 2013: 829040, 2013.

35. Piche T, Barbara G, Aubert P, Bruley des Varannes S, Dainese R, Nano JL, Cremon C, Stanghellini V, De Giorgio R, Galmiche JP, et al: Impaired intestinal barrier integrity in the colon of patients with irritable bowel syndrome: Involvement of soluble mediators. Gut 58: 196-201, 2009.

36. Zhou Q, Zhang B and Verne GN: Intestinal membrane permeability and hypersensitivity in the irritable bowel syndrome. Pain 146: 41-46, 2009.

37. Camilleri $\mathrm{M}$ and Gorman $\mathrm{H}$ : Intestinal permeability and irritable bowel syndrome. Neurogastroenterol Motil 19: 545-552, 2007.

38. Van Itallie CM, Fanning AS, Bridges A and Anderson JM: ZO-1 stabilizes the tight junction solute barrier through coupling to the perijunctional cytoskeleton. Mol Biol Cell 20: 3930-3940, 2009.
39. Fanning AS and Anderson JM: Zonula occludens-1 and -2 are cytosolic scaffolds that regulate the assembly of cellular junctions. Ann N Y Acad Sci 1165: 113-120, 2009.

40. Hamada K, Shitara Y, Sekine S and Horie T: Zonula Occludens-1 alterations and enhanced intestinal permeability in methotrexate-treated rats. Cancer Chemother Pharmacol 66: 1031-1038, 2010.

41. Al-Sadi R, Khatib K, Guo S, Ye D, Youssef M and Ma T: Occludin regulates macromolecule flux across the intestinal epithelial tight junction barrier. Am J Physiol Gastrointest Liver Physiol 300: G1054-G1064, 2011.

42. Zeissig S, Bürgel N, Günzel D, Richter J, Mankertz J, Wahnschaffe U, Kroesen AJ,Zeitz M,Fromm M and Schulzke JD: Changes in expression and distribution of claudin 2, 5 and 8 lead to discontinuous tight junctions and barrier dysfunction in active Crohn's disease. Gut 56: 61-72, 2007.

This work is licensed under a Creative Commons Attribution-NonCommercial-NoDerivatives 4.0 International (CC BY-NC-ND 4.0) License. 